\title{
Portal da Transparência e o acesso à informação: um estudo do portal da transparência e o controle social em três municípios do estado de Pernambuco
}

\author{
Alessandra Carla Ceolin ${ }^{1}$ \\ José Aldo Cavalcanti de Almeida ${ }^{2}$ \\ Maria do Carmo Maracajá Alves ${ }^{3}$
}

\begin{abstract}
RESUMO
A implementação da Lei de Acesso à Informação tem como princípio atender ao Direito Público Administrativo, no tocante à publicidade, onde qualquer cidadão pode tomar ciência de fatos ocorridos nessa esfera. Assim, a facilidade de navegação nos portais corporativos é ponto significativo para atendimento desse princípio. O presente artigo possui como objetivo, analisar o conteúdo e layout de apresentação das informações do site Portal da Transparência, nos municípios pernambucanos de Recife, Olinda e Jaboatão dos Guararapes. O estudo possui natureza descritiva e qualitativa, fundamentado na análise bibliográfica científica, bem como, na análise das legislações específicas: Lei 12.527, de 18 de novembro de 2011 e a Lei Complementar, $\mathrm{n}^{\circ} 101$ de 04 de maio de 2000. Além disso, foram consultadas e coletadas informações disponíveis nos sítios eletrônicos dos municípios selecionados. O modelo de análise observa a disponibilização e o detalhamento dos ícones de consultas ao sistema, sua consistência no portal e a praticidade quanto à utilização de tal ferramenta, levando em conta a flexibilidade, facilidade entendimento, clareza, confiabilidade e atualização tempestiva das informações oferecidas pelos municípios. Os resultados obtidos demonstram um visível atendimento às práticas e determinações do sistema de informação nos portais, para o alcance da eficiência e eficácia desejada ao que diz respeito às boas práticas da transparência e a accountability. Observa-se que a temática em questão traz contribuições às quais estimulam os cidadãos a exercerem efetivamente, com maior participação, a fiscalização, para o controle e gerenciamento da aplicação dos recursos públicos do seu município.
\end{abstract}

Palavras chaves: Transparência, Administração Pública, Sistema de informação.

\section{A study of the "Portal of Transparency" and social control in three municipalities of the state of Pernambuco, Brazil.}

\begin{abstract}
The implementation of the Brazilian Access to Information Act has as its basic principle meet the Public Administrative Law, with regard to advertising, where any citizen can become aware of events that occurred in this sphere. Thus, the ease of access to corporate websites is relevant to meet this principle. This paper aims to analyze the content and presentation layout information of the Transparency Portal site in Pernambuco State, Brazil, regarding the example of tree municipalities: Recife, Olinda and Jaboatão dos Guararapes. The study has a descriptive and qualitative nature, based on the scientific literature review, as well as the analysis of specific legislation: Law N. 12.527 of 18 November 2011 and Complementary Law No. 101 of May 4, 2000. In addition, we consulted and

\footnotetext{
${ }^{1}$ Doutora. Professora do Departamento de Administração da Universidade Federal Rural de Pernambuco (UFPRE). Rua Dom Manoel de Medeiros s/n., Dois Irmãos, Recife-PE. E-mail: alessandra.acc@gmail.com

${ }^{2}$ Bacharel em Administração Pública pela Universidade Federal Rural de Pernambuco. Pós-graduando em Gestão de Custos e Controladoria, Faculdade de Ciências da Administração de Pernambuco (FCAP).

${ }^{3}$ Bacharel em Administração. Mestranda do Programa de Pós-Graduação em Administração e Desenvolvimento Rural da UFRPE.
} 
collected information available on the websites of selected municipalities. The analysis model observes the availability and the details of queries to the system icons, consistency in portal and practicality in the use of such a tool, taking into account the flexibility, ease understanding, clarity, timely reliability and timeliness of information provided by municipalities. The results show a visible service practices and determinations of the information system on the portals to achieve efficiency and desired effectiveness about best practices of transparency and accountability. It is observed that the issue in question brings contributions that encourage citizens to exercise effectively, with greater participation, supervision, for the control and management of the use of public resources of the municipality.

Key words: Transparency, Public administration, Information system.

\section{INTRODUÇÃO}

Um tema de grande relevância e responsabilidade para os gestores da Administração Pública Brasileira vincula-se à obrigatoriedade, prevista em lei, de transmitir à sociedade a prestação de contas da utilização dos recursos públicos. O Layout do sítio internet, utilizado para o acesso a estas informações, deve ser de fácil compreensão, com o objetivo de possibilitar aos cidadãos um acesso didático às informações. Para tal, surgem os portais eletrônicos, como ferramentas de grande alcance no exercício da democracia, sobre a prestação de contas, culminando com o denominado efetivo controle social.

As ações da Administração Pública devem ser propostas e analisadas dentro de normas previstas na legislação, visando qualidade e credibilidade perante a sociedade. Segundo o que estabelece o art. $5^{\circ}$ da Constituição Federal (CF) de 1988, o direito à informação é essencial no controle jurisdicional da transparência na gestão pública. A Carta Magna afirma que o cidadão tem o direito a receber dos órgãos públicos, informações de seu interesse particular ou coletivo, ressalvado os casos em que o sigilo seja imprescindível à segurança do Estado e da sociedade (BRASIL, 1988). Deste modo, todas as informações geradas pelo Estado em nome da sociedade é um bem público, das quais todos os cidadãos têm acesso.

Após a promulgação da $\mathrm{CF}$, e de maneira complementar, no que tange à gestão relacionada à transparência governamental e acesso às informações, a publicação da Lei Complementar $\mathrm{n}^{\mathrm{o}} 101$ de 04 de maio de 2000, conhecida como Lei de Responsabilidade Fiscal (LRF), estabeleceu instrumentos de transparência da gestão fiscal ao instituir normas de finanças públicas, voltadas para a responsabilidade na gestão fiscal, por relatórios resumidos ou extensivos da execução orçamentária, de modo a facilitar o acompanhamento pela sociedade (BRASIL, 2000). E de maneira adicional, a Lei Complementar 131/2009, acrescentou dispositivos à LRF e ampliou a institucionalização da transparência pública (BRASIL, 2009). 
Reforçando esta "filosofia" da Administração Pública, em dar publicidade dos seus atos e agir de forma a obedecer aos princípios da legalidade, moralidade e eficiência; convém destacar as melhorias dos serviços públicos à sociedade, com divulgação de tais informações para a transparência. Diante disto, foi promulgada a Lei $\mathrm{n}^{\circ} 12.527 / 2011$, a qual procura adequar sobre o acesso às informações praticadas pelos agentes públicos (BRASIL, 2011). A Lei de Acesso as Informações (LAI), regulamenta o direito previsto na Constituição, de qualquer pessoa solicitar e receber dos órgãos e entidades públicos, de todos os entes e poderes, informações públicas por eles produzidas ou custodiadas (BRASIL, 2011).

Dessa forma, considerando que a Administração Pública se encontra em uma fase gerencial, no momento em que o Estado procura oferecer serviços de qualidade à população, fazse necessário, que os diversos entes públicos, realizem prestações de contas à sociedade referentes às diversas destinações dos valores captados, no intuito de promover o fiel acompanhamento para os verdadeiros financiadores das ações governamentais.

Ainda neste sentido, a legislação em vigor visa, não apenas o acompanhamento da gestão da máquina pública por parte da sociedade, mas também, limitar a ação do administrador, a fim de manter o Estado com equilíbrio dos recursos orçamentários, da captação ou o aporte de recursos e o gasto público, com vistas a alcançar os reais objetivos propostos. Tudo isso é necessário, pois, as ações promovidas pelo Estado precisam estar incutidas do atributo da publicidade, à qual promoverá transparência às aplicações, objetivos e continuidade dos programas do governo (BRASIL, 2011).

Para que tais determinações alcancem seu real objetivo de transmitir informações à sociedade, convém destacar que as publicações realizadas pelos diversos entes federados precisam ser compreendidas por todos os interessados. Desta maneira, estas informações precisam ser ofertadas numa linguagem capaz de transformar dados em informações, passivas de interpretações, não apenas para os gestores públicos, mas, para todo e qualquer cidadão leigo na matéria que venha a ser verificada, sob pena de sofrer sanções segundo a legislação vigente (BRASIL, 2009).

Neste sentido, a Gestão Governamental tem procurado se adequar à evolução proporcionada no ambiente tecnológico. Esse aspecto, aliado à necessidade de acompanhamento da gerência e destinação dos recursos da sociedade, visa promover publicidade e entendimento às ações implantadas pelo Estado.

Diante do exposto, esta pesquisa tem como objetivo geral verificar o alcance do Portal da Transparência de municípios da Região Metropolitana do Grande Recife, para o exercício do 
controle social a partir do acesso à informação ao cidadão sobre os recursos públicos. A contribuição desta pesquisa consiste em apresentar e interpretar o Portal da Transparência; expor e dialogar com as legislações voltadas à transparência e, analisar de que forma ocorre a publicidade na Gestão Orçamentária em três municípios da Região Metropolitana do Recife.

Por último, ressalta-se que cabe ao Poder Legislativo, em todas as esferas, com auxílio dos seus respectivos Tribunais de Contas, estabelecer regras para o controle e utilização dos recursos arrecadados e disponíveis. Estas medidas são os guias para a elaboração dos demais planos e programas nacionais, regionais e setoriais. Esta necessidade é cada vez maior, devido ao clamor da população por seriedade na Administração Pública, para a fiel execução dos planejamentos e prestação dos serviços com qualidade.

\section{FUNDAMENTAÇÃO TEÓRICA}

\subsection{Transparência na Administração Pública}

Segundo Stiglitz (1999), a transparência se constitui da diminuição das assimetrias informacionais, ou seja, a informação deve ser apresentada de forma clara e limpa, num formato ajustado, com o menor número de falhas possíveis na gestão, para atender aos cidadãos e os agentes estatais. Todo esse controle tem rigor, pois tenta expor ao cidadão as melhores práticas de gestão, para evitar atos ilícitos que poderiam ser cometidos no setor público. Sendo assim, com maior clareza e maior disposição de acesso às informações, a sociedade se beneficia pela capacidade de avaliar melhor a ação pública governamental.

Cruz et al. (2012) afirma que somente a disponibilidade de dados e informações não caracteriza o ente público como transparente, ou seja, não basta para cumprir a Lei. E ainda, afirma ser errônea a percepção de que publicação é princípio de transparência, pois, para que esse ato seja assim configurado, esta ação deve ser condicionada à possibilidade do acompanhamento objetivo e claro da execução orçamentária e das finanças públicas, sendo necessário expor a sua definição real, e em tempo real.

Ainda, conforme os autores supracitados, o nível de transparência das informações ofertadas numa gestão pública municipal, em pesquisa realizada, analisou e identificou as características e os indicadores socioeconômicos dos municípios, e a sua influência do entendimento da transparência. Assim, validou-se a vivência de abjetos que se considerou como nível de transparência, ponderados como conflitantes ao desenvolvimento socioeconômico dos municípios pesquisados. Esperou-se neste estudo, que tal associação mostrasse resultados 
diretamente proporcionais, ou seja, quanto maior a condição socioeconômica da população, maior o nível de transparência dos questionados municípios.

A transparência é um dos princípios da governança pública, e as iniciativas que visem aperfeiçoar os mecanismos de transparência de informações acerca da gestão são consideradas como boas práticas de governança. Num cenário real, a transparência tem por finalidade/necessidade expor as atividades realizadas pelos gestores públicos, de forma concisa, para que os cidadãos tenham além de acesso, o devido entendimento da realização proferida pelos gestores governamentais, no tocante ao atendimento à representação que lhes foi confiada (CRUZ; SILVA; SANTOS, 2009).

Reforçando este entendimento, Figueiras (2011) revela que a transparência é defendida como regra fundamental da gestão pública. Esta obrigatoriedade é executada para tornar os governos responsáveis diante do público. Assim, a perspectiva de uma política da publicidade é fornecer um argumento normativo para o conceito de accountability, no sentido de aprofundar a democracia e fortalecer os processos de gestão pública. Viccari et al. (2009), afirma ainda que, publicidade e transparência são díspares, pois, a transparência conglomera, tanto os números como os atos da gestão, elementos próprios da publicidade, tendo a necessidade de que as informações sejam facilmente assimiladas e interpretadas pela população.

A transparência das informações é considerada uma ferramenta de transformação do governo, dando-a qualidade e segurança. Esta é considerada uma forma de prática, que ajudaria no combate a baixa confiança dos cidadãos, no que tange a corrupção, o mau desempenho, a baixa prestação de contas e o abuso de poder por funcionários públicos. (GRIMMELIKHUIJSENE; WELCH, 2012).

Entende-se que a falta de transparência nos atos administrativos afasta a população da gestão pública, podendo ocorrer a omissão da sociedade. Motivos como estes, mostram que se aposta que as ações que propiciam aumento no nível de transparência, por conseguinte de confiabilidade, dos atos governamentais criam condições para o conhecimento da sociedade nas medidas de controle social (SOARES, 2013).

Soares (2013) ainda avalia que as informações oriundas da internet, são consideradas como um meio eficiente para estabelecer a transparência às informações, considerando que os sistemas de consultas on-line autorizam aos usuários, um filtro na busca de informações requeridas por cada indivíduo. Disto isto, pode-se afirmar que há importância nesta oferta para a relação da sociedade com o governo. 
Diante desse contexto, Hood (2001) define a transparência, como sendo um elemento chave de extrema relevância à gestão pública, que permite inclusive, a redução de custos e tempo na publicidade das transações econômicas e na promoção da democracia. Por ser a democracia um passo fundamental às discussões, resultando num governo democrático legítimo para as reformas no serviço público. Com essa abertura, é possível que haja a informações e seja incumbido o princípio da transparência para a promoção da accountability.

\subsection{Accountability}

Identifica-se o termo accountability com a importância da responsabilização no que se refere ao controle, fiscalização e avaliação dos agentes públicos. Porém ainda não é apresentado na literatura um consenso em relação ao seu conceito.

Estabelece Schedler (1999), que a accountability é usada como ferramenta de cobrança às respostas dos governantes. Isso ocorre, por causa das deficiências advindas das informações públicas. Desde então, surge um novo paradigma de gestão pública, com o empenho de elevar os níveis de eficiência, com mais atenção no que se refere à ética, à moral e à transparência na administração pública, à accountability (MATIAS-PEREIRA, 2009).

A legislação brasileira assegura a transparência, ao definir o direito de informação e, ao impor um determinado padrão ético à administração pública, em todas as esferas de poder governamental, e em todos os níveis federativos (GOMES FILHO, 2005). Muito embora, as obrigações legais, e a transparência estão intimamente alistadas à forma de repasse da informação, e ainda, à responsabilidade na prestação de contas (accountability) em decorrência da responsabilidade da gerência de recursos públicos.

A accountability pode ser considerada como de notória relevância ao exercício da autoridade, de acordo com bases legítimas de ação do Estado na sociedade (FEREJOHN, 1999). Desta maneira, é dever das instituições políticas elaborar mecanismos de prestação de contas à sociedade, com a premissa de reduzir a razão de Estado a uma razão do público e permitir o controle deste sobre aquele. Nesse sentido, o conceito de accountability permite consolidar uma diferenciação entre o público e o privado, e proporciona formas de gestão pública abertas à participação da sociedade.

\section{PROCEDIMENTOS METODOLÓGICOS}

Trata-se de um estudo de caso nos municípios de Recife, Olinda e Jaboatão dos Guararapes, da Região Metropolitana do Recife - Pernambuco - que tem por finalidade a 
verificação das práticas implementadas pelos gestores municipais para atender às exigências da Lei de Acesso Informação.

Com vistas a aprofundar a temática, procedeu-se inicialmente uma pesquisa descritiva e bibliográfica em livros, artigos científicos e monografias. Na sequência, realizou-se uma análise de legislações específicas (Lei 12.527 de 18 de novembro de 2011 e a Lei Complementar $\mathrm{n}^{\mathrm{o}} 101$ de 04 de maio de 2000, a LRF). Além disso, foram consultadas e coletadas informações disponíveis nos websites dos municípios, objeto do estudo.

O desenvolvimento gradual deste trabalho visa explanar a problemática apresentada, fazendo uso da verificação dos sítios eletrônicos das cidades em questão, observando e analisando os dados e layouts, das informações e serviços disponíveis nos portais, utilizando a plataforma de busca on-line do Google (www.google.com.br). Tal instrumento, segundo Paiva e Zuccolotto (2009), seria a forma mais simples para um cidadão leigo em "tecnologia de informação" localizar a homepage (website) de seu município.

Em relação ao estudo do problema de pesquisa, foi utilizada a abordagem qualitativa, apropriada para demonstrar os resultados da gestão em relação ao planejamento da administração municipal. Fez-se uso da análise qualitativa, pela não utilização de instrumental estatístico na análise de dados (RICHARDSON, 2007).

A coleta de dados foi desenvolvida, tendo como recorte analítico, o intervalo decorrido do início do ano de 2014 ao primeiro trimestre do ano de 2015. Este período é pertinente por conter as informações mais recentes disponíveis dos respectivos sítios. E estão aliadas às verificações das práticas de transparência implementadas pelos gestores, dos municípios de Recife, Olinda e Jaboatão dos Guararapes.

\section{ANÁLISE E DISCUSSÃO DOS RESULTADOS}

\subsection{Portais da Transparência do Portal nos Municípios Pesquisados}

Em cumprimento ao que determina as Leis Federais de Responsabilidade Fiscal e de Acesso à Informação, visando assegurar ao cidadão uma maior visibilidade das ações do governo municipal, através da boa e correta aplicação dos recursos públicos, é disponibilizado o acesso ao Portal da Transparência a todo o cidadão. Esse portal contém informações sobre a execução orçamentária e financeira do município, bem como de todos os órgãos e entidades. Primeiramente serão apresentadas as funcionalidades dos portais investigados (Recife, Olinda 
e Jaboatão dos Guararapes). Logo após, fora realizada a discussão dos resultados sobre as funcionalidades e o atendimento desses portais à legislação vigente.

\subsubsection{Apresentação do Portal da Transparência Recife - PE}

A Prefeitura do Recife apresentou à população o seu Portal da Transparência, em abril de 2013, a fim de lhes conferir visibilidade às ações do Governo Municipal. Nesse município, o portal é alimentado e gerenciado pela Controladoria Geral do Município (CGM), em parceria com a Empresa Municipal de Informática (EMPREL).

Trata-se de uma ferramenta que funciona como um canal de comunicação com o cidadão, visto que, viabiliza uma maior fiscalização e participação popular, ao disponibilizar informações sobre a execução orçamentária e financeira municipais, e ao permitir o acompanhamento da aplicação dos recursos públicos. A tela inicial do portal da Prefeitura de Recife pode ser visualizada na Figura 1.

Figura 1 - Portal de acesso à informação da Prefeitura de Recife

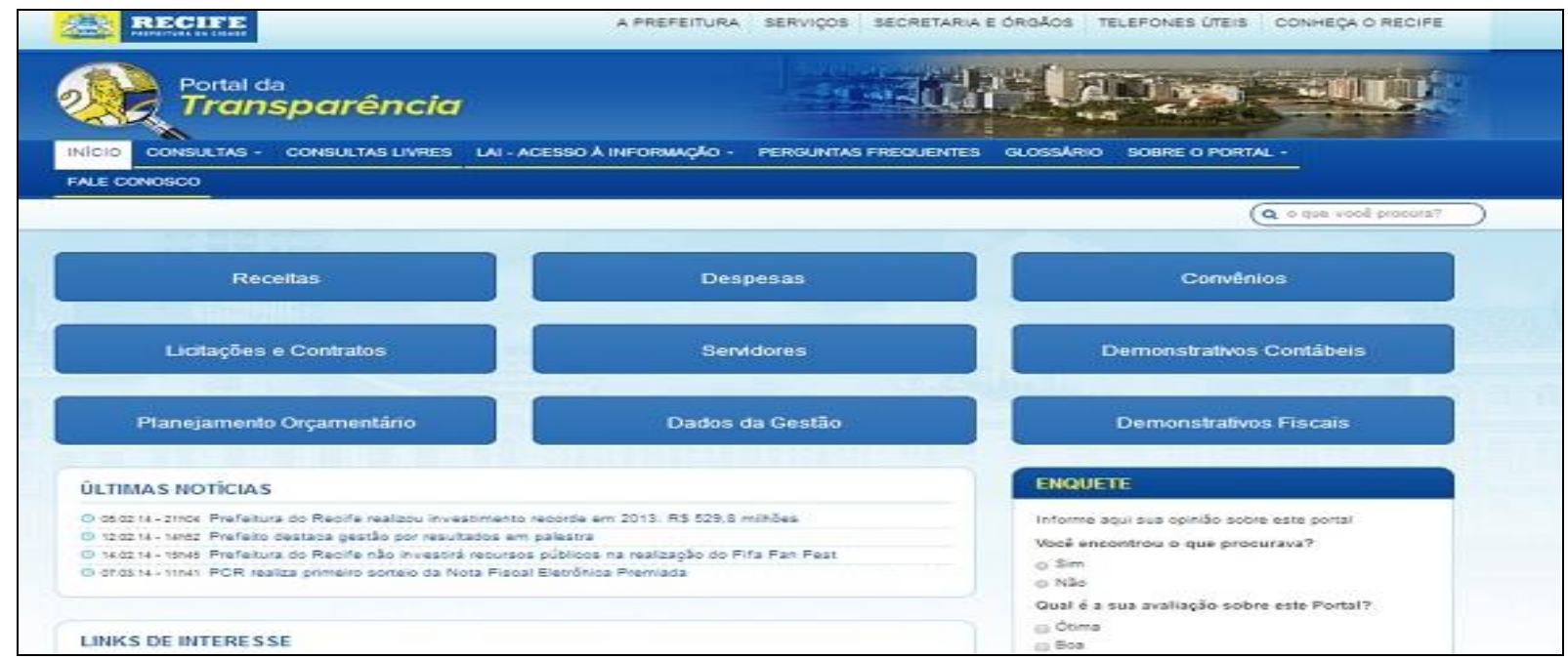

Fonte: Portal da Transparência da prefeitura do Recife (2015).

O Portal da Transparência da Prefeitura do Recife é facilmente identificado ao entrar na página da Prefeitura de Recife (http://www2.recife.pe.gov.br/). Estando na página inicial um link de acesso ao Portal da Transparência (parte superior do website) ou diretamente no website do Portal da Transparência (http://portaltransparencia.recife.pe.gov.br/). Neste se encontra a barra de menu principal, que apresenta itens essenciais para a navegação, os quais são eles: I) Consultas; II) Consultas Livres; III) Acesso às Informações; IV) Perguntas Frequentes; V) Glossário; VI) Sobre o Portal; VII) Fale Conosco. 


\section{Consultas}

a) Receitas: Nesse ícone de acesso é permitido ao usuário verificar: Receita Total; Receita Detalhada; Consultas Livres e os Dados Abertos.

b) Despesas: No primeiro item, dito "despesas", é permitido ao usuário verificar os seguintes relatórios: Despesa Total; Despesa Detalhada por Órgão/Unidade; Despesa Detalhada por Credor/Empenho; Despesa Funcional Programática; Consultas Livres e os Dados Abertos.

c) Convênios: Disponibiliza informações gerais sobre os convênios firmados pelos órgãos e entidades da administração pública municipal, apresentando uma relação com os anos em que o órgão celebrou convênios, gerando o extrato resumido, emitido pela Secretaria de Finanças.

d) Licitações e Contratos: Disponibiliza informações gerais sobre o tema em referência sob dois módulos: Portal de Compras e Contratos.

e) Servidores: Traz informações sobre a remuneração e o cargo dos servidores, a partir dos filtros ano, mês, órgão, categoria e cargos.

f) Demonstrativos Contábeis: Permite o acesso à discriminação de: saldo das contas de receitas e despesas orçamentárias; saldo financeiro do exercício do Município; saldo patrimonial; orçamento previsto por órgão do Município e o nível de liquidação; e, orçamento previsto por ações programadas. O sistema disponibiliza ainda, a lista de balanços, balancetes e demonstrativos, de acordo com o ano selecionado. Nesse tópico é possível visualizar: Balancetes da Execução Orçamentária (Todas as Fontes); Balanço Orçamentário Consolidado; Balanço Financeiro Consolidado; Balanço Patrimonial Consolidado; Demonstrativo da Execução (Programas por Órgão); Demonstrativo da Execução (Ações por Programas).

g) Planejamento Orçamentário: Confere ao cidadão a possibilidade de acessar as diretrizes, os objetivos e as metas propostas pelo Município durante quatro anos. Nesse item estão: Plano Plurianual (PPA); Lei de Diretrizes Orçamentárias (LDO); Lei Orçamentária Anual (LOA); Detalhamento da Despesa por Elemento (DDE).

h) Dados da Gestão: Permite o acesso às informações gerais sobre a gestão: o plano de previdência e saúde dos servidores; audiências públicas; dívidas com terceiros; dívidas de longo prazo; o percentual constitucional dos gastos com educação e saúde; os créditos líquidos e certos; os valores repassados pela União; e, a gestão e geração dos resíduos sólidos. Visualiza-se nesse tópico também: Reciprev; Audiências Públicas; Precatórios; Resultados do Tesouro; Dívida Fundada; Vinculações Constitucionais; Dívida Ativa; Transferências Recebidas da União; Plano Metropolitano de Resíduos Sólidos (PMRS). 
i) Demonstrativos Fiscais: Permite ao usuário o acesso a Relatórios da Lei de Responsabilidade Fiscal; Prestações de Contas da Administração Direta e Indireta; Prestações de Contas e Pareceres do TCE (prestações de contas do município junto ao TCE).

\section{II) Consultas Livres}

O usuário acessa, através de o menu realizar consultas cruzadas uma ferramenta para comparar os dados financeiros, cruzando com outros municípios e períodos, bastando para isto, seguir os passos apresentados da página.

\section{III) Acesso as Informações}

Neste tópico fica a apresentação e consulta sobre a Lei de Acesso a Informação (LAI), que surge para o usuário um sub-menu com os seguintes títulos:

a) Apresentação (LAI): Em breves linhas, apresenta a Lei $n^{\circ} 12.527 / 2011$.

b) Perguntas Frequentes: Traz as perguntas mais recorrentes no que diz respeito à Lei.

c) Consulta à Lei (LAI): Disponibiliza os links diretos para a legislação federal e municipal referente ao acesso à informação.

d) Pedido de Informação: Oferece ao usuário a possibilidade de realizar um pedido de informação, a partir do devido preenchimento do formulário que consta no corpo da página.

e) Acompanhe seu Pedido: Possibilita ao cidadão/usuário, acompanhar seu pedido de informação o qual foi solicitada e protocolada.

f) Endereços e Responsáveis: Enumera todos os entes da administração pública municipal direta e indireta, com seus respectivos contatos (endereço e telefone) e suas autoridades administrativa, classificadora e de monitoramento, em conformidade com a LAI;

g) Local de Atendimento: Faz o registro do local para atendimento presencial a questões referentes à LAI.

\section{IV) Perguntas Frequentes}

São questionamentos mais recorrentes de usuários acerca dos principais temas no Portal da Transparência;

\section{V) Glossário}

Apresenta o significado dos termos utilizados no Portal, divididos por classe de assuntos: a) Finanças públicas; b) Despesas; c) Receitas. 


\section{VI) Sobre o portal}

É uma demonstração do portal ao usuário contendo submenu de:

a) Apresentação do portal: Em breves linhas, apresenta o Portal da Transparência do Recife. b) atualização de dados: Detalha os órgãos responsáveis pelas informações do Portal, a periodicidade de atualização e o sistema de onde são extraídas.

c) Legislação: Elenca os links referentes às normas que, de alguma forma, têm relação com o Portal.

d) Manual de navegação: Disponibiliza manual com informações de navegação no portal.

\section{VII) Fale Conosco}

Onde o cidadão (que não é obrigado se identificar caso não queira resposta) pode encaminhar suas dúvidas, denúncias, reclamações, sugestões e elogios sobre as atuações dos órgãos e entidades da Administração Pública Municipal, sendo visualizados pela Ouvidoria Geral que é responsável por todos esses encaminhamentos.

\subsubsection{Apresentação do Portal da Transparência Olinda - PE}

Cumprindo o que determina a Lei Federal de Responsabilidade Fiscal e de Acesso à Informação e seguindo o princípio de participação popular, que norteia a administração pública municipal, a Prefeitura de Olinda mantém publicidade de informações no Site da Transparência, onde estão disponíveis todas as informações sobre a gestão financeira da cidade. O Portal da Transparência da cidade de Olinda pode ser visualizado na Figura 2.

Figura 2 - Portal da transparência da Prefeitura de Olinda

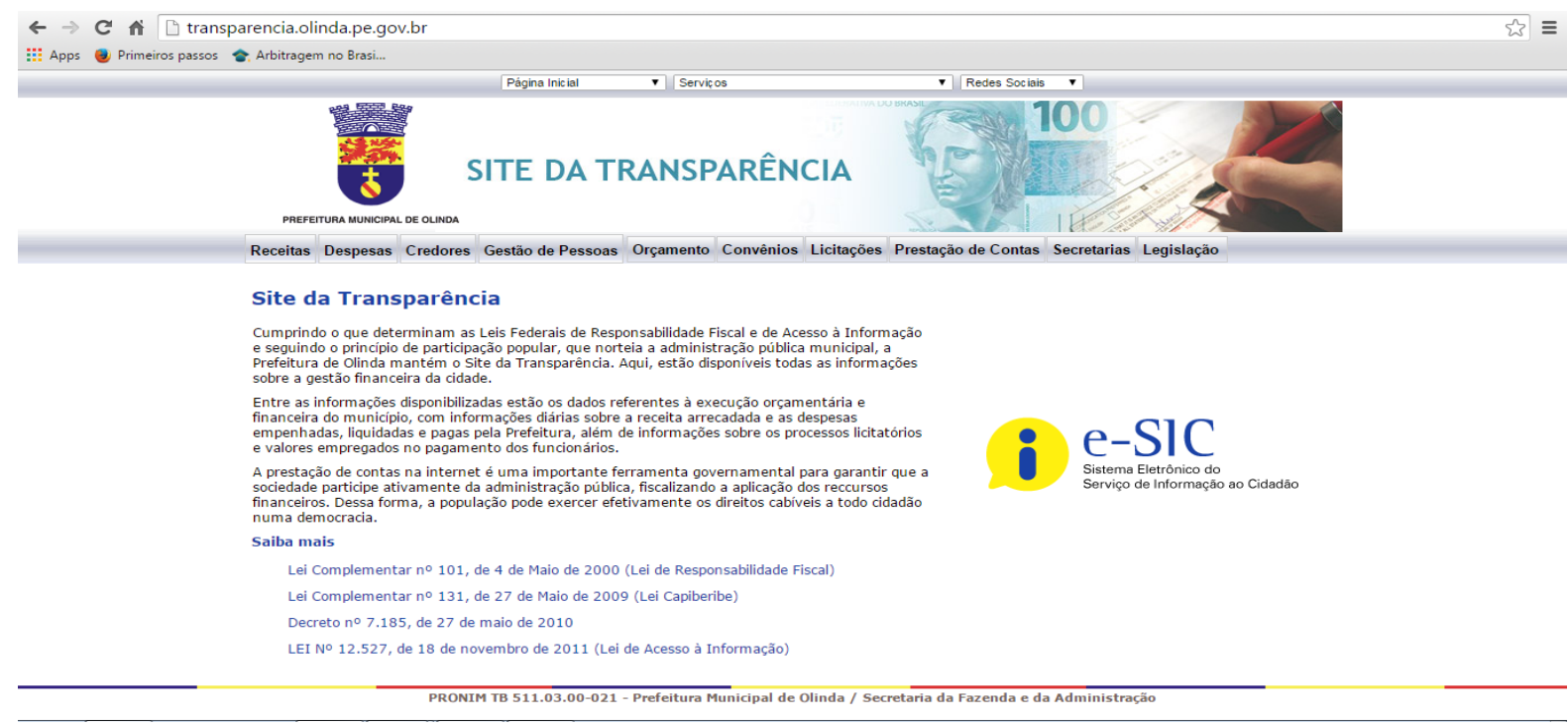

Fonte: Prefeitura Municipal de Olinda (2015). 
O Portal da Transparência é facilmente acessado no sítio virtual da Prefeitura de Olinda (http://www.olinda.pe.gov.br), sendo um dos itens do menu da prefeitura. O portal da transparência da cidade de Olinda também pode ser acessado diretamente em (http://transparencia.olinda.pe.gov.br/). Na página inicial do Portal da Transparência encontrase o тепи que apresenta os itens para a navegação, conforme figura 2, são eles: a) Receitas; b) Despesas; c) Credores; d) Gestão de Pessoas; e) Orçamentos; f) Convênios; g) Licitações; h) Prestações de Contas; i) Secretarias; j) Legislação.

\section{Consultas ao Portal da Transparência de Olinda}

a) Receitas: Com este botão de acesso é permitido ao usuário verificar: Arrecadações da Receita, por Natureza de Receita e por Fonte de Recurso; Receitas Diárias; Ajuda.

b) Despesas: Com este botão de acesso é permitido ao usuário verificar: Classificação Institucional; Função; Programa de Governo; Ação de Governo; Natureza da Despesa; Fonte de Recursos; Esfera Administrativa; Despesas Diárias; Empenhos a Pagar e Ajuda.

c) Credores: Com este botão de acesso é permitido ao usuário verificar: Credores; Ajuda;

d) Gestão de Pessoas: Com este botão de acesso é permitido ao usuário verificar: Remuneração; Ajuda;

e) Orçamento: Com este botão de acesso é permitido ao usuário verificar: Plano Plurianual (PPA); Lei de Diretrizes Orçamentárias (LDO) e a Lei Orçamentária Anual (LOA).

f) Convênios: Com este botão de acesso é permitido ao usuário verificar: Receita; União e Estado.

g) Licitações: Com este botão de acesso é permitido ao usuário verificar: Licitações do Município de Olinda e ao Portal do Cidadão do Tribunal de Contas de Pernambuco.

h) Prestações de Contas: Com este botão de acesso é permitido ao usuário verificar: Prestação de contas enviada ao TCE; Prestação de Contas Anual; Controle de processos junto ao TCE; Relatórios da Lei de Responsabilidade Fiscal até 2014 e os Relatórios da Lei de Responsabilidade Fiscal a partir de 2015.

i) Secretarias: Com este botão de acesso é permitido ao usuário verificar: Todos os departamentos e órgãos da prefeitura de Olinda que são monitorados por uma autoridade responsável pela aplicação e efetivação da Lei Acesso Informação dentro da administração municipal.

j) Legislações: Com este botão de acesso é permitido ao usuário verificar: Leis e Decretos; Instruções Normativas e o Diário Oficial. 
i) Serviços: Onde o cidadão no ícone Atendimento do Contribuinte, onde poderá ser acessado vários serviços, a janela fale conosco que reporta suas solicitações, reclamações, sugestões e ou denúncias.

\subsubsection{Apresentação do Portal da Transparência da Prefeitura do Jaboatão dos Guararapes-PE}

Cumprindo o que determinam as Leis Federais de Responsabilidade Fiscal e de Acesso à Informação e seguindo o princípio de participação popular, que norteia a administração pública municipal, a Prefeitura do Jaboatão dos Guararapes mantém o Site da Transparência. No Portal da Transparência da cidade do Jaboatão dos Guararapes (figura 3), estão disponíveis informações sobre a gestão financeira da cidade.

Figura 3 - Portal da transparência da Prefeitura do Jaboatão dos Guararapes

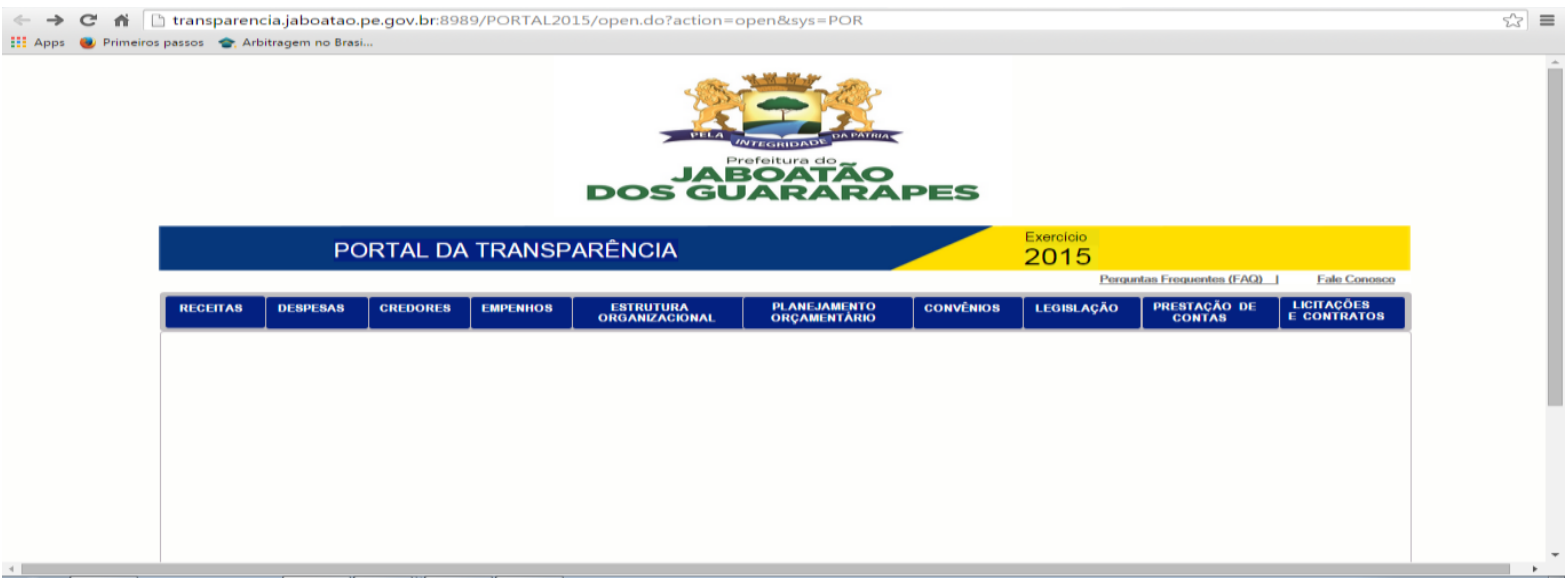

Fonte: Prefeitura municipal do Jaboatão dos Guararapes (2015).

O Portal da Transparência é facilmente acessado no sítio virtual da prefeitura do Jaboatão dos Guararapes (http://www.jaboatao.pe.gog.br), sendo um dos itens do menu da prefeitura. O portal da transparência da cidade de Jaboatão dos Guararapes também pode ser acessado diretamente em (http://transparencia.Jaboatao.pe.gov.br/). Na página inicial do Portal da Transparência o menu que apresenta os itens essenciais para a navegação conforme figura 3 são eles: a) Receitas; b) Despesas; c) Credores; d) Empenho; e) Estrutura Organizacional; f) Planejamento Orçamentário; g) Convênios; h) Legislação; i) Prestações de Contas; j) Licitações e contratos; 1) Fale Conosco.

\section{Consultas ao Portal da Transparência do Jaboatão dos Guararapes}

a) Receitas: Com este botão de acesso é permitido verificar os Lançamentos e as Previsões da Receita. 
b) Despesas: Com este botão de acesso é permitido ao usuário verificar Despesas por Unidade Gestora (UG).

c) Credores: Com este botão de acesso é permitido ao usuário verificar o Cadastro de Credores.

d) Empenho: Com este botão de acesso é permitido ao usuário verificar a Consulta de Empenho e a classificação funcional programática.

e) Estrutura Organizacional: Com este botão de acesso é permitido ao usuário verificar: Secretarias e órgãos; Organograma Institucional e a Lei Complementar n ${ }^{\circ}$ 16/2013 e a LEI Complementar $\mathrm{n}^{\circ} 15 / 2013$.

f) Planejamento Orçamentário: Com este botão de acesso é permitido ao usuário verificar: Plano Plurianual (PPA); Lei de Diretrizes Orçamentárias (LDO); Lei Orçamentária Anual (LOA) e as Audiências Públicas (orçamentos).

g) Convênios: Com este botão de acesso é permitido ao usuário verificar: Receita; União e Estado.

h) Legislação: Com este botão de acesso é permitido ao usuário verificar: Leis e Decretos; Instruções Normativas e o Diário Oficial.

i) Prestações de Contas: Com este botão de acesso é permitido ao usuário verificar: a Lei de Responsabilidade Fiscal e a Prestação de Contas Anual.

j) Licitações e Contratos: Com este botão de acesso é permitido ao usuário verificar: Licitações e Contratos.

l) Fale Conosco: Onde o cidadão pode encaminhar suas dúvidas, denúncias, reclamações, sugestões e elogios sobre as atuações dos órgãos e entidades da Administração Pública Municipal, sendo visualizados pela Ouvidoria Geral que é responsável por todos esses encaminhamentos.

\subsection{Discussão dos Resultados}

Ao analisar o portal das prefeituras do Recife, Olinda e Jaboatão dos Guararapes do Estado de Pernambuco, verifica-se que os mesmos dispõem de informações, em seus respectivos websites, de maneira transparente e de fácil acesso do cidadão. Verificou-se, também, que essas informações podem ser detalhadas quanto ao nível de entendimento e satisfação das necessidades do cidadão/usuário. 
De acordo com o instrumento desenvolvido por Oliveira Neto e Riccio (2001) para avaliar esta satisfação para os usuários quanto ao sistema de informação, são consideradas relevantes as variáveis de acordo com classificação dos fatores de:

1) Praticabilidade (é a característica que facilita à utilização do sistema, levando em conta a flexibilidade; o fácil entendimento; a clareza; a disponibilidade; a confiabilidade e atualização);

2) Precisão (é a maneira de efetuar cálculos corretos e sem erros. Esta dimensão considera a capacidade de precisão dos cálculos e a satisfação do usuário em relação a esta precisão);

3) Disponibilidade (é a capacidade de fornecer a informação atualizada e desejada no tempo certo, com suporte e treinamento);

4) Adequação da Informação (corresponde à forma e o conteúdo da informação sob a visão do usuário/cidadão. Os aspectos mais relevantes nessa dimensão são informações completas, suficiente para a atividade do usuário, fornecimento dos relatórios e de forma adequada).

Levando em consideração esses fatores, elaborou-se um comparativo com os portais pesquisados. Esse comparativo pode ser visualizado no quadro 1.

Quadro 1 - Comparativo dos portais pesquisados

\begin{tabular}{|c|c|c|c|c|}
\hline Cidades & Praticabilidade & Precisão & Disponibilidade & $\begin{array}{l}\text { Adequação da } \\
\text { Informação }\end{array}$ \\
\hline Recife & $\begin{array}{l}\text { Possibilita com } \\
\text { disponibilidade o } \\
\text { acesso e navegação } \\
\text { no portal fácil e } \\
\text { compreensão das } \\
\text { informações. }\end{array}$ & $\begin{array}{c}\text { Prove ao Cidadão com } \\
\text { qualidade o acesso aos } \\
\text { relatórios, econômico e } \\
\text { financeiro do } \\
\text { município. }\end{array}$ & $\begin{array}{l}\text { Possibilitam interação } \\
\text { e facilidade no acesso } \\
\text { a informação do portal } \\
\text { através do botão fale } \\
\text { conosco e ouvidoria. }\end{array}$ & $\begin{array}{c}\text { O site apresenta } \\
\text { informações diversas } \\
\text { para as atividades de } \\
\text { consulta as } \\
\text { informações ao } \\
\text { cidadão/usuário no } \\
\text { portal. } \\
\end{array}$ \\
\hline Olinda & $\begin{array}{c}\text { Possibilita com } \\
\text { disponibilidade boas } \\
\text { condições de acesso } \\
\text { e navegação no } \\
\text { portal com } \\
\text { informação de fácil } \\
\text { compreensão. }\end{array}$ & $\begin{array}{c}\text { Provem ao Cidadão } \\
\text { com qualidade o acesso } \\
\text { aos relatórios, } \\
\text { econômico e financeiro } \\
\text { do município. }\end{array}$ & $\begin{array}{l}\text { Possibilita interação } \\
\text { ao e acesso do portal } \\
\text { através do botão fale } \\
\text { conosco e da } \\
\text { ouvidoria. }\end{array}$ & $\begin{array}{c}\text { O site apresenta } \\
\text { informações diversas } \\
\text { para as atividades de } \\
\text { consultas e informação } \\
\text { ao cidadão/usuário no } \\
\text { portal }\end{array}$ \\
\hline $\begin{array}{c}\text { Jaboatão dos } \\
\text { Guararapes }\end{array}$ & $\begin{array}{c}\text { Possibilita com } \\
\text { condições boas de } \\
\text { acesso, no entanto } \\
\text { demanda uma } \\
\text { atenção passo à passo } \\
\text { aos ícones de acesso. }\end{array}$ & $\begin{array}{c}\text { Provem ao Cidadão } \\
\text { com qualidade o acesso } \\
\text { aos relatórios, } \\
\text { econômico e financeiro } \\
\text { do município. }\end{array}$ & $\begin{array}{l}\text { Possibilita interação } \\
\text { ao e acesso do portal } \\
\text { através do botão fale } \\
\text { conosco e da } \\
\text { ouvidoria. }\end{array}$ & $\begin{array}{c}\text { O site apresenta } \\
\text { informações diversas } \\
\text { para as atividades de } \\
\text { consultas e informação } \\
\text { ao cidadão/usuário no } \\
\text { portal }\end{array}$ \\
\hline
\end{tabular}

Fonte: elaborado peles autores. 
Diante disso, percebe-se que dos três sites, o de Recife e Olinda são mais completos, possuem acesso mais fácil, com rápida visualização da informação, por outro lado o de Jaboatão dos Guararapes precisa desenvolver melhor, mais atrativo estimular a procura a todos os usuários da informação uma vez que possui menos atributos e possibilidades ao acesso à informação.

Observando a realização ao longo da produção permite classificar tais sítios com elevado nível de compreensão e enquadramento às exigências impostas pelas legislações que norteiam tais determinações.

\section{CONSIDERAÇÕES FINAIS}

Este estudo teve como objetivo a análise da acessibilidade do Portal da Transparência municipal em três cidades do Estado de Pernambuco (Recife, Olinda e Jaboatão dos Guararapes), a fim de contribuir para o fortalecimento de acesso ao portal, para o cidadão com interesse de informações claras e atualizadas da movimentação dos recursos públicos. Sua realização permitiu observar o modelo de gestão adotado no portal das prefeituras que de modo consistente venha priorizar os esforços em atender o cidadão.

De maneira que estes recursos sejam bem aplicados e os serviços possam ser prestados com melhor qualidade e com mais eficiente, por isso os administradores públicos devem com clareza demonstrar interesse em desenvolver maneiras ou modelos de gestão e controle dos recursos públicos para a realização de política pública à sociedade.

Uma administração transparente permite ao cidadão possa participar na gestão e no controle da administração pública e para que esta participação se torne realidade é necessário que ele possa ter capacidade de compreender as informações divulgadas pelos gestores. Com isso utilizar estes instrumentos de informação para acompanhar a movimentação dos recursos financeiros, exercendo um papel fundamental do cidadão, a identificação de mau uso deste recurso, suas ocorrências impendem o crescimento do município e em consequência o crescimento do País, fato que pode ocasionar a diminuição do bem-estar social.

O cidadão/usuário do Portal da Transparência, através desse trabalho poderá obter uma consciência crítica necessária para o exercício do controle social. O fortalecimento dos instrumentos de participação depende da participação de cada cidadão a respeito da importância do seu crescimento social nas questões políticas. 


\section{REFERÊNCIAS}

BRASIL. Constituição da República Federativa do Brasil. Brasília: Senado Federal, 1988.

BRASIL. Presidência da República. Casa Civil. Lei Complementar n⿳0101, de 4 de maio de 2000. Estabelece normas de finanças públicas voltadas para a responsabilidade na gestão fiscal e dá outras providências. Brasília, DF, 2000. Disponível em: <http://www.planalto.gov.br/ccivil_03/leis/lcp/lcp101.htm>. Acesso em: 13 mai. 2015.

BRASIL. Presidência da República. Casa Civil. Lei Complementar n. 131, de 27 de maio de 2009. Acrescenta dispositivos à Lei Complementar n. 101, de 4 de maio de 2000. Brasília, DF, 2009. Disponível em: <http://www.planalto.gov.br/ccivil_03/leis/lcp/lcp131.htm>. Acesso em 13 mai. 2015.

BRASIL. Presidência da República. Casa Civil. Lei n. 12.527, de 18 de novembro de 2011. Diário Oficial da União: República Federativa do Brasil, Brasília, DF, 18 nov. 2011.

Disponível em: <http://www.planalto.gov.br/ccivil_03/_ato2011- 2014/2011/lei/112527.htm>. Acesso em: 24 jun. 2015.

CRUZ, C.F. et al. Transparência da gestão pública municipal: um estudo a partir dos portais eletrônicos dos maiores municípios brasileiros. Revista de administração pública; v. 46, $\mathrm{n}$. 1, jan./fev. 2012. p. 153-176.

CRUZ, C.F.; SILVA, L.M.; SANTOS, R. Transparência da gestão fiscal: um estudo a partir dos portais eletrônicos dos maiores municípios do estado do Rio de Janeiro. In: Encontro de Administração da Informação, II, Recife, 2009. Anais... Anpad, 2009.

FEREJOHN, J. “Accountability and authority”. In: PRZEWORSKI, A.; STOKES, S.; MANIN, B. (orgs.). Democracy, accountability, and representation. Cambridge: Cambridge University Press. 1999.

FIGUEIRAS, Fernando. Transparência, Publicidade e Accountability. Scielo, Belo Horizonte, 2011. Disponível em <http://www.scielo.br/pdf/ln/n84/a04n84.pdf>. Acesso em 20 mai 2015

GOMES FILHO, A.B. O desafio de implementar uma gestão pública transparente. In: Congresso Internacional Del Clad Sobre La Reforma Del Estado Y De La Administración Pública, X, Santiago. Anais... Clad, 2005.

GRIMMELIKHUIJSEN, S. G., \& WELCH, E. W. Developing and testing a theoretical framework for computer-mediated transparency of local governments. Public Administration Review, 2012. 562-571.

HOOD, C. “Transparency”. In: CLARKE, P.B.; FOWERAKER, J. (Orgs). Encyclopedia of Democratic Thought. London: Routledge, 2001.p. 700-704.

MATIAS-PEREIRA, J. Manual da gestão pública contemporânea. 2.ed. São Paulo: Atlas, 2009.

OLIVEIRA NETO, J. D.; RICCIO, E. L. Desenvolvimento de um Instrumento para Mensurar a Satisfação do Usuário de Sistemas de Informações Através do Método Survey. In: 13 
Asian-Pacific Conference On International Accounting Issues. Rio de Janeiro (RJ), 2001. Disponível em http://www.rausp.usp/artigo.asp?num_artigo. Acesso em 15 jun 2015

PAIVA, C.P.R.; ZUCCOLOTTO, R. Índice de transparência fiscal das contas públicas dos municípios obtidos em meios eletrônicos de acesso público. In: ENCONTRO DA ANPAD, XXXIII, São Paulo, 2009. Anais... Anpad, 2009. Disponível em

<http://www.anpad.org.br/admin/pdf/APS332.pdf >. Acesso em: 15 jun. 2015.

RICHARDSON, Roberto Jarry. Pesquisa social: métodos e técnicas. 3ed. - 7. reimpr - São Paulo: Atlas, 2007. Disponível em <http://pt.scribd.com/doc/226198537/01-RichardsonPesquisa-Social-MCtodos-e-TCcnicas-pdf-PdfCompressor-643562\#scribd>. Acesso em 15 jun. 2015.

SOARES, Laura Letsch. Transparência em compras públicas: Proposta de um Índice da Transparência na Gestão de Compras Públicas Aplicado aos Websites de Municípios Brasileiros com mais de 100 mil habitantes. 2013. 168 f. Dissertação (Mestrado em Contabilidade). Florianópolis: UFSC, 2013.

SCHEDLER, A. Conceptualizing Accountability. In: A. Schedler, L. Diamond, \& M. Plattner, (Ed.) Self-Restraining State - Power and Accountability in New Democracies. Boulder: Lynne Rienner Publishers, 1999. Disponível em: <http://www.follesdal.net/projects/ratify/TXT/Paris_Schedler.PDF>. Acesso 15 jun. 2015.

STIGLITZ, J.E. On liberty, the right to know and public disclosure: the role of transparency in public life. Oxford Amnesty Lecture, 1999.

VICCARI, A. Jr et al. Lei de Responsabilidade Fiscal Comentada: Lei Complementar $\mathbf{n}^{\circ}$. 101, de 04 de maio de 2000. 6. ed. São Paulo: Atlas, 2009. 